\title{
The Holistic Analysis of Multicultural Teaching Framework: Capturing Teachers' Pauses and their Hybrid and Fluid Multicultural Practices
}

\author{
Juan A. Freire \\ Brigham Young University \\ U. S. A. \\ Verónica E. Valdez \\ University of Utah \\ U. S. A.
}

\begin{abstract}
James Banks's framework for determining the levels of integration of multicultural content in teachers' pedagogy has long been a tool used by researchers worldwide. This article introduces the Holistic Analysis of Multicultural Teaching Framework that rethinks Banks's framework to allow research analysis to capture the hybrid and fluid aspects of teachers' multicultural practices as well as the pauses in their practices over time. Data from a study on U.S. dual language teachers' classroom implementation of multicultural practices serves to illustrate the utility of the Holistic Analysis framework in analyzing teachers' multicultural practices. Implications for teacher educators and researchers are discussed.
\end{abstract}

KEYWORDS: Teacher education, multicultural education, research methodology, teacher research, pedagogy.

Multicultural Education: A Path to Educational Equity?

Banks's Framework for Levels of Integration of Multicultural Content in Teachers' Practices

Rethinking a Framework for the Analysis of Teachers' Multicultural Teaching The Holistic Analysis of Multicultural Teaching Framework

Conclusions

References

Author Contact

The integration of multicultural content into teachers' practices has been a goal in teacher education since the advent of the 1960's civil rights movement in the U.S. (Banks, 2016). Since then, multicultural education has grown into an established discipline internationally that works to transform education through the preparation of educators for the needs of a diverse society. One of the most recognized frameworks is Banks's model (1988), which identifies five dimensions (content integration, knowledge construction, prejudice reduction, equitable pedagogy, and empowering school culture) to facilitate the implementation of multicultural education. We focused on the first dimension that, since the late 1980s, James A. Banks $(1988,2002,2009,2016)$ has called the "Levels of 
Integration of Multicultural Content." Teachers, schools, and districts have adopted Banks's framework to facilitate the integration of multicultural content into a teacher's pedagogy. It has also been used to research and analyze teachers' multicultural education understandings and practices (Agirdag et al., 2016; Brown \& Livstrom, 2020; Huang, 2002; Scott, 2014; Silva \& Patton, 1997). In a similar vein, we, as researchers, adopted Banks's levels of integration of multicultural content to examine teachers' multicultural classroom practices and how these practices changed over time. We now argue that, as a research tool, Banks's framework needs to be rethought and expanded to better capture the complexity of teachers' multicultural practices over time.

The purpose of this article is to propose the Holistic Analysis of Teachers' Multicultural Teaching Framework as a research analysis tool. We build on the insights Banks's framework offered us in our year-long qualitative study of eight U.S. teachers who implemented multicultural practices in their Spanish-English elementary dual language classrooms. In the Holistic Analysis Framework, we made a discursive shift from "level" to the term "mode" to better describe the unique combination of styles in which teachers implemented multicultural practices. We also highlighted three elements in the Holistic Analysis Framework: (1) the concept of pauses, referred to as the pause mode, when lesson plans are void of multicultural content and could not be categorized into any of Banks's "modes"; (2) the concept of hybridity as designated by the use of the hybrid mode to account for when multicultural lessons included elements of more than one of Banks's "modes"; and (3) the concept of fluidity, captured through the collection of observations over time, when teachers' lesson plans moved fluidly back and forth across "modes" instead of following a linear developmental sequence as suggested in Banks's framework.

In this article, we begin by tracing the emergence of multicultural education and its goal of educational equity. We then introduce Banks's framework as an analytical tool to research teachers' multicultural practices, followed by our rethinking of Banks's framework based on insights gained when applying it to our data analysis. Using examples from our research, we introduce the Holistic Analysis Framework to more fully capture the pauses, hybridity, and fluidity present in teachers' practices currently not made visible in Banks's framework. We conclude by discussing why these changes are essential to teacher education and discuss their implications for future research on teachers' multicultural practices.

\section{Multicultural Education: A Path to Educational Equity?}

The U.S. civil rights movements heralded an unprecedented push for multicultural education by minoritized communities as part of their efforts to attain educational equity (Banks, 2016; Gay, 2018). Banks and Banks (2013) defined multiculturalism as:

A philosophical position and movement that deems that the gender, ethnic, racial, and cultural diversity of a pluralistic society should be reflected in all 
of the institutionalized structures of educational institutions, including the staff, the norms, the values, the curriculum, and the student body. (p. 355)

This stance established the basis for the realization of multicultural education in response to the problematic racial ideologies in mainstream teaching practices perpetuating societal inequities. These ideologies and practices promoted racism (Ladson-Billings \& Brown, 2008) and overlooked minoritized communities' epistemologies and contributions. When educational institutions included minoritized communities' contributions, it was often from "a deficit perspective that view[ed]...[minoritized] students' backgrounds-particularly their race, culture, social class, and language-as problems to be fixed" (Nieto et al., 2008, p. 177). In response to minoritized communities' calls for educational equity, many educational institutions initiated actions to ensure equity in teaching practices. These efforts fundamentally changed the field of education. However, much of this work did not go far enough, often lacking a critical stance leaving issues of power, such as racism, overlooked (Sleeter \& Bernal, 2004). These educational endeavors resulted in the adoption of superficial multicultural teaching approaches that focused on holidays and "single-group studies" of one ethnic group (Banks, 2016; Grant \& Sleeter, 2013). Thus, although these efforts brought awareness of minoritized communities, it did little to increase equitable educational opportunities for minoritized students (Banks, 2016). Today, critical educators worldwide continue to advocate for the need for systemic changes in teachers' pedagogies that move us beyond Banks's "contributions and additive approaches" (LadsonBillings \& Brown, 2008, p. 154) toward critical methodologies that lead to educational equity.

\section{Banks's Framework for Levels of Integration of Multicultural Content in Teachers' Practices}

Banks's (2016) framework describes four levels of integration of multicultural content: the contributions, the additive, the transformative, and the social action levels. The contributions level focuses on the selective inclusion of ethnic heroines' and heroes' positive contributions, such as when a book on Frida Kahlo is read during "Hispanic" History month in the U.S. using criteria from mainstream society and not from ethnic communities. The additive level makes content-based cultural connections to a mainstream perspective without changing its structure or framework, such as when educators incorporate the role of American Indians into discussions of the U.S. Thanksgiving holiday as part of the curriculum. The transformative level aims to develop critical thinking with a restructured curriculum from several ethnic perspectives and viewpoints. A discussion of the U.S. Thanksgiving holiday, for example, may extend to talking about issues of conflict and first contact across the world. The social action level aims "to educate students for social criticism and social change and to teach them decision-making skills" (Banks, 2016, p. 161). This level allows for discussions of immigration, for example, that may lead to students writing letters to politicians or the media to advance the issues they identify as impacting their community. Banks identifies these four levels of integration of multicultural content as presenting 
varying levels of difficulty to enact. He offers the social action level as the most challenging, followed by the transformative level, the additive level, and the contributions level, suggesting a developmental progression for integrating multicultural content in classroom practices.

Throughout Banks's work, he has made statements, such as:

It is unrealistic to expect a teacher to move directly from a highly mainstream-centric curriculum to one that focuses on decision making and social action. Rather, the move from the first to higher levels of multicultural content integration is likely to be gradual and cumulative. (Banks, 2016, p. 163)

Lending credence to the theory of different levels having varying difficulty, research on teachers' multicultural practices shows educators prefer and more readily understand and use the easier contributions and additive levels. These easier levels are followed by the transformative level, with the social action level being the least understood or practiced (Agirdag et al., 2016; Brown \& Livstrom, 2020; Huang, 2002). In contrast, our qualitative research found variation in teacher preferences was not a function of difficulty levels. Instead, these variations were due to teachers' resistance, their gaps in knowledge, their unawakened critical/sociopolitical consciousness, and their discomfort with the transformative and sociopolitical modes' emphasis on raising issues they viewed as controversial (Freire, 2014).

Banks's framework is useful because it allows researchers to capture the range of teachers' multicultural practices in the classroom. It provides a clear way to distinguish between teachers' different approaches to implementing multicultural content in their classrooms and addresses culture and critical consciousness as elements of multicultural teaching practices. However, complications have emerged in the use of Banks's model due to its grounding in a developmental approach to teachers' growth in their multicultural education practices and its inability to capture the complexities that emerge in teachers' practices over time.

\section{Rethinking a Framework for the Analysis of Teachers' Multicultural Teaching}

Since its introduction, many have utilized Banks's framework to study and analyze teachers' multicultural practices in the classroom (Agirdag et al., 2016; Brown \& Livstrom, 2020; Huang, 2002; Scott, 2014; Vecellio, 2012). While critiques of Banks's framework have emerged, it remains a valuable research tool. Our interest in Banks's framework was as a tool to capture teachers' multicultural practices. However, during our use of Banks's framework for analysis of teachers' multicultural practices, we found challenges and limitations that affirmed earlier critiques and raised new ones. In the next section, we offer examples from our research on implementing multicultural practices in the classroom that showcase the elements of teachers' practices we were unable to fully capture using Banks's 
framework as currently expressed. We accompany these examples with illustrations of how we were able to analyze these elements using the Holistic Analysis Framework. We begin by offering a brief overview of the study and the analysis processes from which we draw our examples.

\section{Research Data and Initial Analysis}

We illustrate the research analysis frameworks' implementation drawing on data collected across a year-long collaborative professional development study. This study examined eight teachers' multicultural beliefs and practices in a Spanish-English dual language program at an urban elementary school with a high number of students designated as English learners and Latinas/os in the U.S. Intermountain West. All the teachers whose classrooms we observed were unfamiliar with how to incorporate multicultural content successfully into their pedagogy. Three teachers identified themselves as Latinas, four as white, and one as white with Greek heritage. The data set included 19 informal conversational teacher interviews and 60 classroom lesson observations focused on an entire video-recorded lesson plan.

A thematic analysis approach (Saldaña, 2009) was used to analyze teacher interviews focused on teachers' beliefs, practices, and sociocultural factors, such as structures and forces, impacting participants' beliefs and practices. Classroom video data of teachers' multicultural practices were analyzed thematically using a priori and emergent coding (Saldaña, 2009) focused on practices promoting cultural competence and critical consciousness using Banks's four levels of multicultural integration. We specifically coded for the characteristics that Banks described for each level. When more than one level was present, we initially categorized the lesson plan based on what Banks defined as the most challenging level for teachers to implement (see Banks's framework section). For example, a lesson with a contributions level and a transformative level was coded as a lesson representative of the transformative level. Banks identified this level as more challenging than the contributions level. Over the school year, we began to identify gaps and elements of Banks' framework that did not fully capture the nuances of teachers' multicultural practices.

\section{Data Re-Analysis}

Subsequent rounds of analysis coded the classroom video recordings for other elements and aspects of teachers' multicultural practices that emerged in our data but were not captured by Banks's framework. Particularly revealing were pauses with no visible evidence of multicultural practices and the prevalence of instances of more than one mode of multicultural content in teachers' classroom practices. Our re-analysis resulted in the Holistic Analysis Framework we advance in this article that allowed us to re-code teachers' practices to include what we termed the "pause" mode and the "hybrid" mode of multicultural content. 
Figure 1

The Hybrid Mode of the Holistic Analysis of Multicultural Teacher Framework
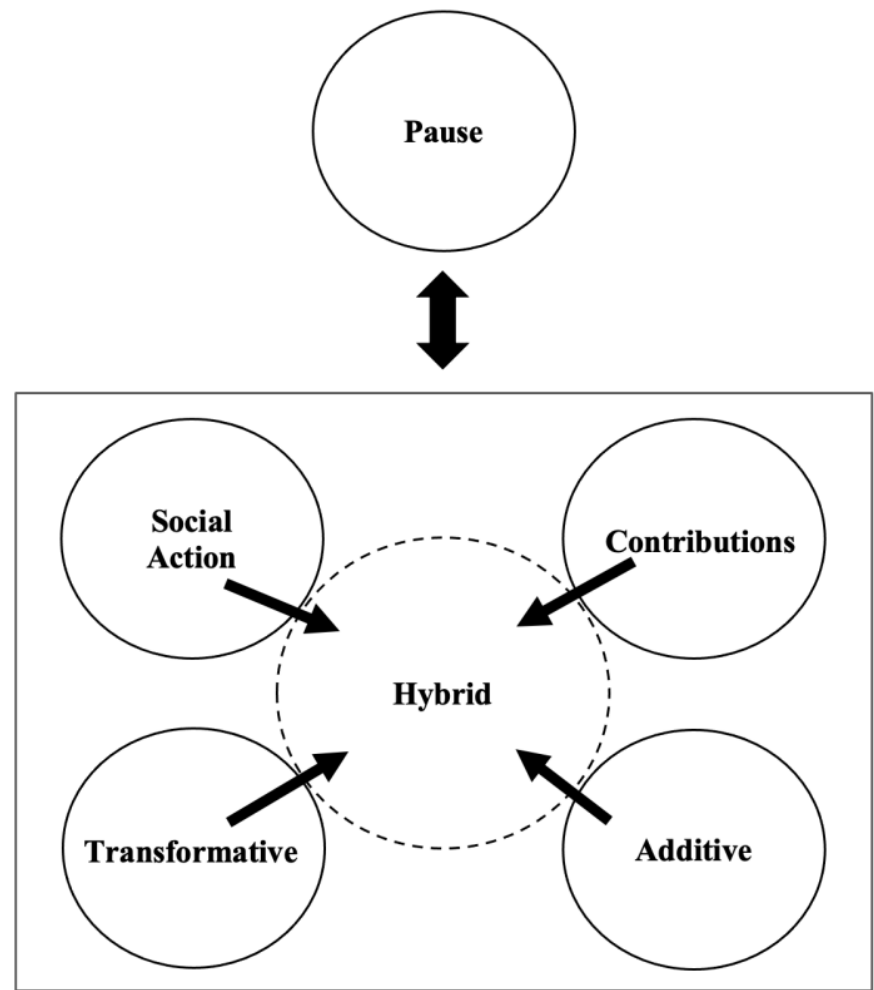

Thus, when a lesson had no multicultural content, it was coded in pause mode rather than receiving no code. When a lesson had elements of the contributions and transformative modes, instead of coding it as the singular transformative mode, we coded it as a hybrid practice under the new "hybrid" mode. Figure 1 illustrates the six modes that are a part of the Holistic Analysis Framework and the modes that teachers drew on to combine into their "hybrid" multicultural practices. In a later section, we provide a more nuanced picture of how we rethought Banks's framework to create our Holistic Analysis of Multicultural Teaching Framework that illustrates how these elements expressed themselves and changed over time.

\section{Rigor and Trustworthiness}

This study met various rigor considerations. One of them was prolonged engagement, which refers to "the investment of sufficient time to achieve certain purposes: learning the 'culture,' testing for misinformation introduced by distortions either of the self or of the respondents, and building trust" (Lincoln \& Guba, 1985, p. 301). The year before the study took place, we facilitated professional development, and Juan (the first author) volunteered at the school through a university partnership that supported this study (Bernal \& Alemán, 2017). This year-long introduction along the year-long collaborative professional development study ensured prolonged engagement. 
We built trustworthiness mainly by meeting confirmability, transferability, and authenticity (Lincoln \& Guba, 1985). Confirmability was achieved through participants' rich quotes and practices depicting themes and main findings provided in this article. Transferability was met by ensuring the proposed holistic analysis of the multicultural teaching framework could be applied to other multicultural research studies. Lastly, authenticity was achieved by grounding the holistic analysis framework that emerged in participating teachers' classroom experiences, practices, and voices.

\section{The Holistic Analysis of Multicultural Teaching Framework}

A principle of the Holistic Analysis Framework is bearing in mind the social context and structural influences of teachers' multicultural practices when analyzing teachers' work, such as institutional structures in schools that discourage teachers' implementation of multicultural practices (Buendía et al., 2003). The eight participating teachers, new to multicultural teaching practices, had different structural forces affecting their work. For example, two of these educators, Ms. Lee and Ms. Parker, were applying for National Board certification. Video recordings they made for the National Board certification were included in our research analysis. A total of 60 lessons, collected across all participating teachers, were first analyzed employing Banks's framework, then re-analyzed using the Holistic Analysis Framework.

One of the first things we found problematic when using Banks's framework was the use of "levels" for each descriptor of multicultural content integration primarily due to its developmental tone. Thus, we began our rethinking of Banks's framework by making a discursive change in the way we talked about teachers' practices, from levels to our use of the term "mode." We found this conveyed styles in which multicultural practices were implemented that could be used alone or in any combination or sequence. Using the term "mode" also allowed us to highlight in our research analysis the pauses and elements of hybridity and fluidity that emerged in teachers' multicultural practices, which we discuss next.

\section{Pauses in Teachers' Multicultural Practices}

In our study, we observed periods of what we labeled pauses, where teachers' practices were void of multicultural elements or where they explicitly chose not to implement modes. Pauses can be enacted in different ways, at different times, and are motivated by multiple factors (Parhar \& Sensoy, 2011; Raider-Roth et al., 2012), including discrimination such as English hegemonic practices, racism, and racist nativism (Hyland, 2005; Pérez Huber, 2011). They can also stem from the need for time to reflect and learn, different structural influences, or deliberate acts of resistance. The term "pauses" is not intended to justify the absence of multicultural teaching practices. Instead, we view the analysis of these pauses as critical to offering better supports to teachers without demonizing them. Many teachers committed to equity are still learning how to implement multicultural pedagogies for educational equity and justice. 
In our study, we documented that part of the reason why these teachers sometimes did not practice multicultural teaching was because of gaps in their knowledge (Freire \& Valdez, 2017). For example, one teacher said: "Knowing how to manage a social justice conversation would be good. I mean, how to bring it up in a positive and productive way." This lack of understanding of how to practice multicultural teaching led to a pause in this teacher's multicultural practices. However, when applying Bank's framework, we found that, although it made the cultural and sociopolitical elements of teachers' practices visible, it did not consider these periods of pause. In our study's analysis of teachers' practices using Banks's framework, 28 out of 60 lessons (47\%) did not have any multicultural elements, making them ineligible to be identified at any of the four levels of multicultural teaching. These 28 lessons were thus excluded. Figure 2A shows our analysis of one teacher's multicultural practices (Ms. Lee) using Banks's framework to depict the nine instances in which her multicultural practices were evident over time out of 23 observed lessons. This analysis offers a limited view of the overall processes and complexities of teachers' multicultural practices over time. Thus, in our Holistic Analysis Framework, we added and coded for a fifth style-the pause mode-to make these elements visible for analysis (Freire, 2014). Use of the pause mode resulted in Figure 2B, which identifies 14 pause mode lessons when applying the Holistic Analysis Framework to analyze Ms. Lee's multicultural practices over time.

\section{Figure 2}

Comparison of Analyses of One Teacher's Practices over Time

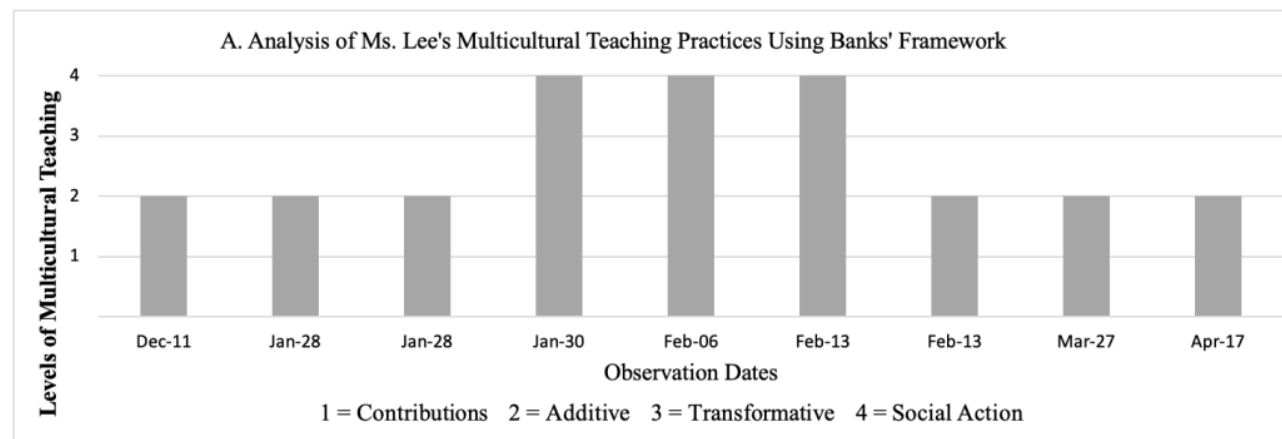

B. Analysis of Ms. Lee's Multicultural Teaching Practices Using the Holistic Analysis Framework

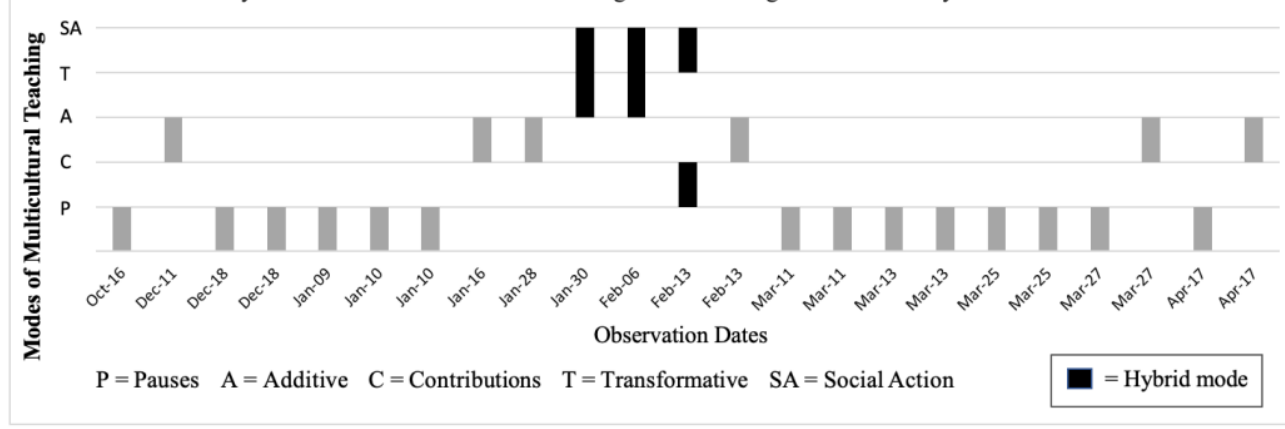

Figure 2. Comparison of Analyses of One Teacher's Practices over Time: (A) Banks' Framework versus (B) The Holistic Analysis of Multicultural Teaching Framework with hybrid mode denoted in bars that include more than 1 of the multicultural teaching styles. 
In capturing teachers' pause mode, some teachers demonstrated a general resistance to using specific modes of multicultural content over time. For example, when asked regarding the addition of sociopolitical elements in her lessons, Ms. Parker expressed her feelings of resistance in the following way: "Highlighting social inequities probably will be hard... I am always a little bit hesitant." This quote shows she made a deliberate choice to resist implementing the transformative or social action modes throughout the school year. In fact, the transformative and social action modes were never observed in her classroom. Instead, she tended to lean toward implementing the less challenging modes. Gorski's (2009) research points to teacher education's failure to prepare and scaffold teachers toward implementing the sociopolitical aspects of multicultural education. Thus, we view these teacher reports as reflecting their underdeveloped critical consciousness and limited awareness of its educational equity implications.

The Holistic Analysis Framework allowed patterns of teacher utilization of the pause mode to be visible. Figure 2B shows that, in Ms. Lee's case, the pause mode was present across trimesters over the school year until April. In fact, we began to observe teachers making choices about implementing multicultural practices amid busy lives shaped by various structural influences. When including teachers' pauses in the analytical research stage, the situational context was an essential element to consider. In our research analysis, the pause mode was most evident in Ms. Lee and Ms. Parker, two teachers who had the most demands placed on them due to the pursuit of their National Board certification at the time of our research. Because they perceived National Board certification as not requiring them to meet their students' cultural or sociopolitical needs, during periods of high intersecting priorities, these teachers chose to prioritize other National Board certification elements. For example, when Juan went to video record these teachers' classroom lessons, on some occasions, they said: "Sorry! I am not doing any culturally relevant stuff. For this lesson, I'm just focusing on the National Board." These teachers perceived the National Board certification process as not requiring them to implement multicultural practices.

The use of the Holistic Analysis Framework also revealed that, although there were pauses that represented general resistance to using multicultural content by some teachers, for other teachers, the collaborative professional development context offered meaningful learning during these pause mode periods. They listened, observed, risked, and made sense of what multicultural teaching should look like before they embarked on implementing it or practicing more challenging modes themselves. Ms. Cox, a first-grade English teacher who used pauses to build towards a transformative mode lesson at the end of the year, offers an example. She taught three lessons: a pause mode lesson in November, another pause mode lesson in January, and a transformative mode lesson in April. Her January pause mode lesson was in language arts, and the topic was positional prepositions. Ms. Cox started this lesson by dictating some sentences. Then, she introduced some prepositions, such as "above," "under," "below," and "beside." She closed this lesson by reading two books that included those prepositions. One of the books talked about vegetables in the garden. Based on examples in the book, Ms. Cox talked about vegetables that people might and might not like. 
Speaking of broccoli, she said, "some people like it, some people don't. We're all different, right? Okay!" Speaking of beets, she said, "So some people like beets, some people don't, that's okay." Despite her intent to teach about respecting each other's cultural differences, Ms. Cox focused only on taste differences and student food preferences, thus, not reflecting any of Banks's four modes. However, this did show her thinking about and attempting to implement a contributions mode despite not succeeding. Adding the pause mode allowed us to capture and better understand the teacher's learning processes over time by comparing lessons such as Ms. Cox's pause mode lessons with those she implemented in other modes.

In Ms. Cox's April end-of-year transformative mode lesson, she built on her learning during the pause mode lessons and embedded transformative elements related to immigration in her lesson about the continents for the social studies content area. With the aid of a large world map poster, Ms. Cox introduced the continents. Then, she pulled out a sock monkey, moved him around the map, and discussed how the sock monkey moved from place to place, explicitly mentioning Mexico since most of her students had Mexican heritage. She asked her students whether they or any of their relatives had moved. After students shared personal experiences, Ms. Cox asked: "Is it okay to move around?" "What does being an immigrant mean?" "Why does it happen?" After asking each of these questions, she debriefed responses with the students and validated immigration as a natural process that needs to be respected and legitimized. Although very nervous, she addressed the topic of immigration in her social studies lesson in ways that led to its transformative mode classification.

Ms. Cox had restructured the curriculum away from a traditional approach in which immigration issues are often overlooked when learning about the continents and included viewpoints that are usually excluded in mainstream teaching. The lesson also had cultural and sociopolitical elements. Students connected immigration experiences to their own lives and shared their experiences as Ms. Cox intended to fight against xenophobia by validating immigration as a natural phenomenon worldwide. However, Ms. Cox's poor choice of a sock monkey to illustrate immigration, offensive to many minoritized immigrants in the United States, showed the learning that remained. Understanding and analyzing Ms. Cox's January pause mode lesson was useful in making sense of Ms. Cox's implementation of multicultural practices in her teaching and the processes involved in her professional growth trajectory.

Focusing on different types of pauses and adding a pause mode to our Holistic Analysis Framework allowed us as researchers to pay attention to the periods when multicultural practices were not present and learn more about the constraints teachers were negotiating. This focus allowed us to provide better supports for teachers' efforts to implement multicultural practices in their classrooms over time, underscoring the importance of accounting for and understanding these pauses. 


\section{Hybridity in Teachers' Practices}

Banks presents his four levels of integration of multicultural content as isolated forms of teaching with the possibility of mixing and blending approaches, writing that they "....are often mixed and blended in actual teaching situations" (Banks, 2016, p. 163). However, this concept is not sufficiently developed in his work to show how these modes may be combined in actual teaching and captured for research purposes. The lack of clarity and examples in Banks's work regarding hybridity and overlap in teachers' practices created tensions in our efforts to analyze and describe their multicultural practices in a single lesson and in lessons over time. For example, when we first analyzed teachers' practices according to Banks's framework, our analysis resulted in Figure 3A, where each singular mode of teachers' integration of multicultural content is evident. However, although it captured similar information about the contributions and additive levels as the Holistic Analysis Framework, Banks's framework could not capture the complex and varied ways teachers combined modes when attempting modes they personally found more challenging. Our analysis of teachers' practices using each analysis framework serves to illustrate this point in Figure 3 . For discussion purposes, we focus on the transformative mode's use in this example.

A total of five transformative mode lessons were identified when using Banks's framework, as seen in Figure 3A.

\section{Figure 3}

Comparison of Analytic Approaches: Banks's Framework versus the Holistic Analysis of Multicultural Teaching Framework

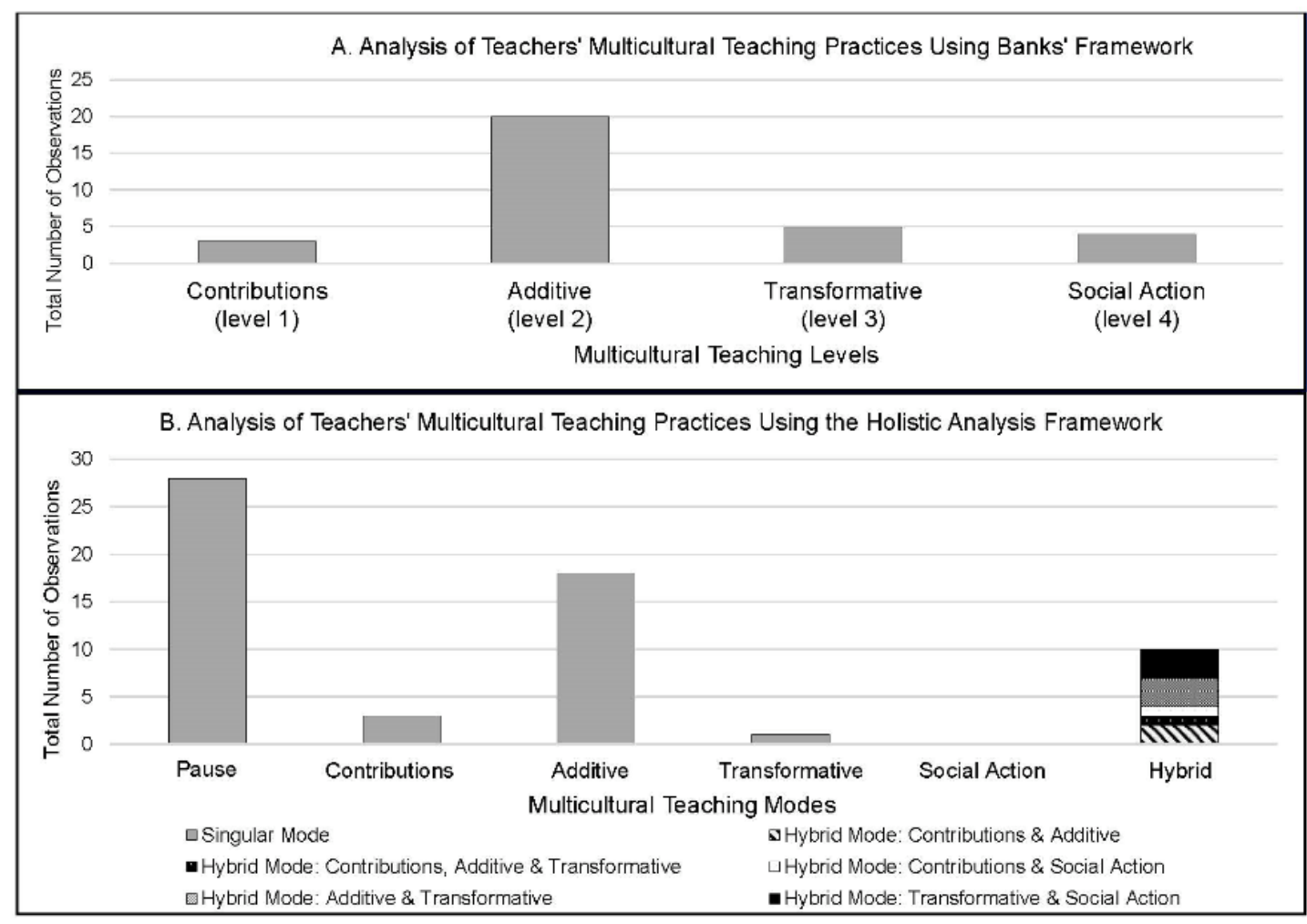


When we re-analyzed teachers' practices supported by the Holistic Analysis Framework, our work categorized lessons based on the presence of one of the singular modes or as a hybrid mode that combined two or more singular modes in the same lesson, as illustrated in Figure 3B. Following the application of the Holistic Analysis Framework, only one of 60 lessons implemented by teachers was coded in a transformative singular mode. However, when coding lessons for those taught in a hybrid mode that combined the transformative mode with one or more singular modes, seven out of 10 hybrid lessons identified included the transformative mode. Figure $3 \mathrm{~B}$ shows the varied ways teachers combined singular modes across the ten lessons in hybrid mode: two contributions-additive lessons, one contributions-additive-transformative lesson, one contributions-social action lesson, three additive-transformative lessons, and three transformativesocial action lessons. Employment of the Holistic Analysis Framework made visible that, when teachers utilized the transformative mode, they most often did this in combination with the other modes.

One of Ms. Nikolaidis's lessons represents a hybrid mode lesson inclusive of additive and transformative elements. This kindergarten teacher did a readaloud of Swing High, Swing Low by Fionna Coward using a traditional reading structure. This book highlights the concept of opposites by following a brother and sister from morning to bedtime over the course of a day. For the additive elements, she linked the story to students' local communities and heritage countries by mentioning a children's museum and a neighborhood park located close to the school, as well as making connections to cultural artifacts in students' lives representative of their heritage cultures. For example, based on a book illustration of the two siblings in the kitchen with their mother, Ms. Nikolaidis said, "Sometimes in the kitchen, we might have things to decorate with because we like certain things." She pointed to some artifacts that the family in the story had in their kitchen. She referenced her Greek heritage and said:

You might have your kitchen with something because it's about your family, where your family is, right? In my kitchen, we would have some spices that we use in the food that we use, like oregano, okay? So, maybe in your kitchen, [a student yells out that he has peppers in his kitchen], it's because of things that you cook in your family because you cook different things than what I cook, right? 'Cuz your family likes different things. What else...? So, Luca, you said peppers? So, did that make you think of something that you wanted to say about your kitchen?

Ms. Nikolaidis used her cultural heritage as a means for students to talk about their culture and cultural differences. She then asked for cultural artifacts students had in their kitchen and validated them. When a student said that peppers, a food often associated with traditional Mexican cuisine and often visible in the kitchens of U.S. households of Mexican heritage, were something he had in his kitchen, Ms. Nikolaidis spoke of the contents of her kitchen. She said that she would not have peppers at her house but would have oregano, lemons, and other traditional spices of Greek cuisine. 
Ms. Nikolaidis also talked about the importance of respecting different cultures. In this part of her lesson, we see that her multicultural teaching is done in an additive mode. First, these teaching elements were "added to a curriculum as appendages instead of being integral parts of a unit of instruction" (Banks, 2016, p. 159), and second, these elements were not critical or challenging of the mainstream structure or curriculum (Banks, 2014). However, within the same lesson, she then used the transformative mode when she guided her lesson toward the sociopolitical issue of racial differences. Ms. Nikolaidis posed questions to students about skin color differences, disrupting internalized oppression and racist views that positioned one skin color as better than another. In one of the book pages, there were people of different races crossing the street. Ms. Nikolaidis pointed at the illustrations of these characters and asked, "So, we've got different people that live in this neighborhood. Do they all look the same?" Students responded with a "No!" In another part of the book in which there were children of different races, she asked about racial differences in which students responded in unison.

Ms. Nikolaidis: The kids all come together; they're from the neighborhood. They're not all the same; [Do] they all have black hair?

Students: No!!

Ms. Nikolaidis: [Do] they all have blonde hair?

Students: No!!

Ms. Nikolaidis: [Do] they all have brown hair?

Students: No!!

Ms. Nikolaidis: Okay, no! Is one kind of color better than another kind of hair color?

Students: No!!

Ms. Nikolaidis: How about their faces? Do they look the same?

Students: No!! Yes!!

Ms. Nikolaidis: Close! Are all your faces the same?

Students: No!!

Ms. Nikolaidis: No!!!! We all come from different places.

Student A: The skin.

Ms. Nikolaidis: The color, see, this kid right here. She has a little bit darker skin, and this girl right here, see on the other page, she has lighter skin, is it better for this kid to be this color?

At this point, some students responded affirmatively and others negatively. Ms. Nikolaidis concluded by talking about the importance of liking your skin color, no matter what color it is. These quotes represent elements of a transformative mode because of their sociopolitical nature. Although the lesson used a book depicting two white children who go with their mother to different parts of the neighborhood, Ms. Nikolaidis brought transformative elements to her multicultural teaching. She did this by noting skin color differences as something positive in the neighborhood depicted in the book and amongst themselves.

This example suggests that teachers can combine different modes in one lesson and even in one activity. In the case of Ms. Nikolaidis, she relied on the less 
challenging additive mode when implementing the transformative mode in her lesson. For the social action mode, teachers expressed being more "hesitant" to apply it, with some teachers like Ms. Nikolaidis not implementing it at all in any of her lessons. The teachers who used this mode always taught it in combination with other modes. When implementing multicultural lessons, these examples of hybridity exemplify that there is no fidelity to a single multicultural teaching mode in teachers' practices, even within an activity such as reading a kindergarten book. Our analysis using the Holistic framework helped reveal that, as teachers gain more experience learning to implement multicultural practices, they begin enacting their practices in more hybrid ways that include modes they view as more difficult for them.

\section{Fluidity in Teachers' Practices}

As we mentioned earlier, we used Banks's model to conceptualize and analyze teachers' multicultural practices. However, we found that his model positioned the learning of multicultural teaching practices as developmental. Although some teachers might appear to follow Banks's developmental trajectory, the emphasis on a developmental course in teacher learning created tensions in our analysis of teachers' practices over time. Vecellio (2012) found a similar tension and critiqued Banks's approach to teachers' multicultural practices, suggesting that teachers' practices can emerge at any level and do not need to follow a specific developmental progression. We believe that, as Ladson-Billings (2009) highlighted in The Dreamkeepers, there is a new generation of multicultural teachers who do not necessarily start their teaching careers as Level 1 teachers integrating content at the contributions level. Although we agree that many teachers develop critical consciousness gradually, our evidence refutes a developmental view of teachers' multicultural practices. It suggests a more fluid and non-linear progression in teachers' practices allowing a more comprehensive range of modes of multicultural teaching to be utilized, sometimes simultaneously and in varying order, as teachers gain more experience and are better able to manage competing priorities.

In Figure 2A, our analysis using Banks's framework contradicts its developmental stance, instead showing fluidity in the movement of Ms. Lee's practices from the additive mode to the social action mode and back to the additive mode. In Figure 2B, the Holistic Analysis Framework addition of the pause and hybrid modes allows a more nuanced depiction of fluidity. It shows that what may appear as a linear process is, in fact, more fluid as teachers move back and forth across modes, enter the process at different modes reflecting what they individually view as less challenging at that point in time, and creatively combining multiple modes as they seek ways to teach and integrate multicultural content in their lessons. As we saw in Ms. Lee's example earlier, she often returned to the pause mode and the additive mode over the school year while introducing and creatively combining these efforts with hybrid, social action, transformative, and contributions mode efforts in January/February. Ms. Lee did not gradually move across levels, as discussed by Banks. Instead, her practices across the school year were fluid, non-developmental, and non-linear. Although most teachers 
gradually learned to implement multicultural practices, as Ms. Lee, they did not often follow a set path. Their teaching practices were dynamic throughout the school year, taking different forms at different times. The Holistic Analysis Framework facilitated analysis that captured these complexities.

\section{Conclusions}

The Holistic Analysis of Multicultural Teaching Framework emphasizes the importance of capturing in context the pauses, hybridity, and fluidity in teachers' instructional practices. Moving away from looking at teachers' practices developmentally, in isolation, and in singular forms led us to the Holistic Analysis Framework. In this framework, our discursive shift to modes, as well as the adding of the pause and hybrid modes to Banks's four levels (contributions, additive, transformative, social action), established six modes that allowed us to capture the fluidity of teachers' practices and reflections over time. The teacher interviews that accompanied the classroom observations offered insights into the factors and learning processes that shaped the mode(s) they used. We illustrated the Holistic Analysis Framework's use in our work with eight U.S. teachers learning to implement multicultural practices, offering a more nuanced picture of teachers' practices within the classroom and how they changed over time.

Social context is vital to consider in teacher education efforts (Buendía et al., 2003). Educators across the globe can identify a great variety of contexts and structures that teacher-researchers need to consider when studying teachers' enactment of multicultural practices. We view social context as fundamental in the Holistic Analysis Framework and consider it critical for anyone who engages in analyzing teachers' instructional practices. It is vital for us as researchers and teacher educators to consider the different professional and personal contexts and structures that shape teachers' choices over time. These factors can lead to fluctuating and dynamic teaching practices as they work to implement new methodologies. Teachers' multicultural practices also emerged in hybrid forms, and teachers often introduced multicultural elements into their lessons through different entry points or combinations of modes.

Pauses in the implementation of multicultural teaching practices are common for pre-service and in-service teachers. Thus, when teachers are in pause mode - a time when it appears teachers are not making progress toward multicultural teaching in their classroom-it is important to take note of it. We believe these pauses have often been overlooked by researchers analyzing teachers' multicultural practices. While we agree that pauses in multicultural teaching have their own set of challenges and tensions and may be perceived as negative, counterproductive, or as a training failure, one of our conclusions is that teacher educators and researchers can benefit from bearing in mind teachers' pauses. In our work, these pauses were useful in capturing how teachers' practices evolved over time in non-linear ways. It allowed us to capture episodes of teachers failing to implement new multicultural teaching practices while they were simultaneously learning ways to implement these new practices from colleagues. 
Thus, these pauses did not necessarily interrupt growth but rather may be a constructive part of teachers' learning process and critical consciousness-raising that simply requires time, support, and an understanding of the demands of teachers' contexts and structures. Despite the benefits of acknowledging these pauses in research with teachers, we highlight that these do not constitute a goal in itself or ideal teaching practices. Multicultural education is not a part-time endeavor. We need to bear in mind that pauses are still mainstream teaching practices that can be hegemonic and oppressive.

The Holistic Analysis Framework builds on Banks's framework to support improved analysis of in-service and pre-service teachers' multicultural teaching practices. Researchers and teacher educators can benefit from accounting for the pauses, hybridity, and fluidity in teachers' everyday classroom practices to gain an understanding of the factors and learning processes teachers experience when working toward adopting new teaching practices that advance quality and liberatory education for minoritized students.

\section{References}

Agirdag, O., Merry, M. S., \& Van Houtte, M. (2016). Teachers' understandings of multicultural education and the correlates of multicultural content integration in Flanders. Education and Urban Society, 48(6), 556-582. https://doi.org/10.1177/0013124514536610

Banks, J. A. (1988). Approaches to multicultural curriculum reform. Multicultural Leader, 1(2), 1-3.

Banks, J. A. (1995). Multicultural education: Historical development, dimensions, and practice. In J. A. Banks \& C. A. M. Banks (Eds.) Handbook of research on multicultural education (pp. 3-24). Macmillan.

Banks, J. A. (2002). An introduction to multicultural education: Issues and perspectives. Allyn \& Bacon.

Banks, J. A. (2009). Teaching strategies for ethnic studies. Pearson Education.

Banks, J. A. (2014). An introduction to multicultural education. Allyn \& Bacon.

Banks, J. A. (2016). Approaches to multicultural curriculum reform. In J. Banks \& C. A. M. Banks (Eds.), Multicultural education: Issues and perspectives (pp. 151-170). Wiley.

Banks, J. A. \& Banks, C. A. M. (2013). Multicultural education: Issues and perspectives. Wiley.

Bernal, D. D., \& Alemán, E., Jr. (2017). Transforming educational pathways for Chicana/o students: A critical race feminista praxis. Teachers College Press.

Brown, J. C. \& Livstrom, I. C. (2020). Secondary science teachers' pedagogical design capacities for multicultural curriculum design. Journal of Science 
Teacher Education, 31(8), 821-840. https://doi.org/10.1080/1046560X.2020.1756588

Buendía, E., Gitlin, A., \& Doumbia, F. (2003). Working the pedagogical borderlands: An African critical pedagogue teaching within an ESL context. Curriculum Inquiry, 33(3), 291-320. https://doi.org/10.1111/1467873X.00264

Freire, J. A. (2014). Spanish-English dual language teacher beliefs and practices on culturally relevant pedagogy in a collaborative action research process (Doctoral dissertation). Retrieved from Proquest.

Freire, J. A., \& Valdez, V. E. (2017). Dual language teachers' stated barriers to implementation of culturally relevant pedagogy. Bilingual Research Journal, 40(1), 55-69. https://doi.org/10.1080/15235882.2016.1272504

Gay, G. (2018). Culturally responsive teaching: Theory, research, and practice. Teachers College Press.

Gorski, P. C. (2009). What we're teaching teachers: An analysis of multicultural teacher education coursework syllabi. Teacher and Teacher Education, 25(2), 309-318. https://doi.org/10.1016/j.tate.2008.07.008

Grant, C. A., \& Sleeter, C. E. (2013). Race, class, gender, and disability in the classroom. In J. A. Banks \& C. A. M. Banks (Eds.). Multicultural education: Issues and perspectives (pp. 59-79). Wiley.

Huang, H. (2002). Designing multicultural lesson plans. Multicultural Perspectives, 4(4), 17-23. https://doi.org/10.1207/S15327892MCP0404_4

Hyland, N. E. (2005). Being a good teacher of Black students? White teachers and unintentional racism. Curriculum Inquiry, 35(4), 429-459.

https://doi.org/10.1111/j.1467-873X.2005.00336.x

Ladson-Billings, G. (2009). The dreamkeepers: Successful teachers of African American children. Jossey-Bass.

Ladson-Billings, G., \& Brown, K. (2008). Curriculum and cultural diversity. In F. M. Connelly, M. F. He, J. Phillion (Eds.), The SAGE handbook of curriculum and instruction (pp. 153-175). SAGE Publications.

Lincoln, Y. S., \& Guba, E. G. (1985). Naturalistic inquiry. SAGE.

Nieto, S., Bode, P., Kang, E., \& Raible, J. (2008). Identity, community, and diversity: Retheorizing multicultural curriculum for the postmodern era. In F. M. Connelly, M. F. He, \& J. Phillion (Eds.), The SAGE handbook of curriculum and instruction (pp. 176-197). SAGE.

Parhar, N., \& Sensoy, Ö. (2011). Culturally relevant pedagogy redux: Canadian teachers' conception of their work and its challenges. Canadian Journal of Education, 34(2), 189-218. Retrieved from http://www.jstor.org/stable/canajeducrevucan.34.2.189 
Pérez Huber, L. (2011). Discourses of racist nativism in California public education: English dominance as racist nativist microaggressions. Educational Studies, 47(4), 379-401. https://doi.org/10.1080/00131946.2011.589301

Raider-Roth, M., Stieha, V., \& Hensley, B. (2012). Rupture and repair: Episodes of resistance and resilience in teachers' learning. Teaching and Teacher Education, 28(4), 493-502. https://doi.org/10.1016/j.tate.2011.11.002.

Saldaña, J. (2009). The coding manual for qualitative researchers. SAGE.

Scott, M. T. (2014). Using the Blooms-Banks matrix to develop multicultural differentiated lessons for gifted students. Gifted Child Today, 37(3), 163168. https://doi.org/10.1177/1076217514532275

Silva, C., \& Patton, M. M. (1997). Multicultural education: Theory to practice. Teacher Education \& Practice, 13(1), 22-38.

Sleeter, C., \& Bernal, D. D. (2004). Critical pedagogy, critical race theory, and antiracist education: Implications for multicultural education. In J. A. Banks, \& C. A. M. Banks (Eds.), Handbook of research on multicultural education (pp. 240-258). Jossey-Bass.

Vecellio, S. (2012). Enacting FAIR education: Approaches to integrating LGBT content in the K-12 curriculum. Multicultural Perspectives, 14(3), 169-174. https://doi.org/10.1080/15210960.2012.697015

\section{Author Contact}

Juan A. Freire, Assistant Professor, freire@byu.edu

Department of Teacher Education, 201 MCKB, Brigham Young University, Provo, Utah, 84602-5099

Verónica E. Valdez, Associate Professor, veronica.valdez@utah.edu Department of Education, Culture, \& Society, College of Education, 1721 Campus Center Dr., SAEC \#3280, University of Utah, Salt Lake City, Utah, $84112-9256$ 